\title{
Determination of the thermal conductivity of some selected roof ceiling materials in Taraba State,
} Nigeria

\author{
Ejeh Samson E. , D. Yabwa, Abuh Samuel O, Yakubu Hassan Koji \\ American University of Nigeria Yola, Nigeria \\ *Corresponding author
}

\begin{abstract}
In our homes, indoor thermal discomfort has been very challenging and it depends on one or more of the materials used either as ceiling board rock used as walling materials; woods used in making doors and wood sample used in making roofing supports the roofing sheet itself or combination of all of them. Observation in the present competitive world reveals that people that are economically favored usually go for the costliest ceiling materials without preference to the thermal conductivity of the most sought after ceiling materials. It is based on this premise that this work designed to determine the thermal conductivity of the most frequently used ceiling materials and to predict the most suitable ceiling materials to be used especially in tropical regions. This research work encompasses the variation of thermal conductivity (with different types) of roofing ceiling. The Lee disc method will be used to determine the thermal conductivity of Plaster of Paris (POP), Polyvinylchloride (PVC) and Aesthetic timber wood. This project shall provide guide for the choice of the types of roof ceiling materials to be used in tropical regions and the rate at which they conduct heat.
\end{abstract}

Keywords: Thermal conductivity, Ceiling materials, Heat flow.

\section{INTRODUCTION}

$\mathrm{T}$ hermal insulators have been used in heat storage system to prevent temperature gradient thereby minimizing heat losses to the surrounding (Turner and Malloy 1988). In housing construction, insulators are used to prevent heat exchange across the boundaries of shelter. These insulating materials are usually made in various types, varieties, and form. Like loose fill rigid board pipes and foam, proper selection of insulating materials is based on the thermal properties which includes the thermal conductivity, specific heat capacity, thermal conductivity, specific heat capacity, thermal resistivity and thermal diffusity (Ayugi, 2009). Thermal insulator is provided by embedding insulation materials at least on the roofing area and the vertical walls of the system. (Novo and Baryon, 2010). Poor thermal insulation in heat losses or heat gain as the case may be. (Suman and Srivastava, 2009). Polyvinyl chloride (PVC), plaster of Paris (POP) and Aesthetic timber ceiling boards are ceiling purpose in Nigeria mainly due to availability in the market or their stunning appearance and not on their low thermal conductivity. However, some of these thermal insulators are not suitable ceiling materials to be used. This work therefore sets to determine among other things the insulation materials that provide better solution as ceiling material in terms of thermal conductivity or thermal resistivity thereby provide a guide for builders.

Series of studies have been carried out to determine the insulating material that provides better solution as ceiling material. Research conducted by (George, Obianwu, Akpabio and Obot, 2010) on the thermal insulation efficiency of some selected material used as ceiling in building design show that the roof ceiling materials Plaster of Paris, Asbestos and suspended ceilings are recommended as ceiling materials with good thermal insulation efficiency when compared with Polyvinyl chloride (PVC) and cardboard.

(Suman et al, 2009) also conducted a research on the influence of thermal insulation on conductive heat transfer through roofing ceiling construction and the result show that treated roof has high thermal resistivity. (Gesa, Newton, Roy and Aondoakaa, 2014), investigated thermal insulation properties of some roofing ceiling materials which result shows that Plaster of Paris provides the best thermal insulation (having low thermal conductivity and high thermal resistivity) when compared to ply wood and isorel (masonite) ceiling board. (Michael, Evelyn, Chinedu, and Arusuedfe, 2012) compared the thermal properties of Asbestos and polyvinyl chloride (PVC) ceiling sheets, the result shows that it has a higher thermal resistivity when compared to Asbestos. (Etuk et al, 2005) conducted a research on the thermal properties of Cocos Nucifera Truck, which shows that coco palm has low thermal conductivity resulting to high thermal resistivity that favor it as interior building insulation materials.

This work is therefore aimed at studying the thermal properties of roofing ceiling and to present a for the production of temperature variation with thickness of the samples as ceiling materials which will be suitable for use in housing construction in tropical regions.

\section{FOURIER'S LAW}

The law of heat conduction, also known as Fourier's law, states that the time rate of heat transfer through a material is proportional to the negative gradient in the temperature and to the area, at right angles to that gradient, through which the heat flows. We can state this law in two equivalent forms: the 
integral form, in which we look at the amount of energy flowing into or out of a body as a whole, and the differential form, in which we look at the flow rates or fluxes of energy locally.

Newton's law of cooling is a discrete analog of Fourier's law, while Ohm's law is the electrical analogue of Fourier's law.

\subsection{Differential form}

The differential form of Fourier's Law of thermal conduction shows that the local heat flux density, $\rho$, is equal to the product of thermal conductivity $\mathrm{K}$, and the negative local temperature gradient, $-\nabla T$. The heat flux density is the amount of energy that flows through a unit area per unit time. $q=-k \nabla T$

$\mathrm{q}$ Is the local heat flux density, $\mathrm{W} \cdot \mathrm{m}^{-2}, \mathrm{~K}$ is the material's conductivity, $\mathrm{W} \cdot \mathrm{m}^{-1} \mathrm{~K}^{-1},-\nabla T$ Is the temperature gradient, $\mathrm{K} \cdot \mathrm{m}^{-1}$.

The thermal conductivity, $\mathrm{K}$, is often treated as a constant, though this is not always true. While the thermal conductivity of a material generally varies with temperature, the variation can be small over a significant range of temperatures for some common materials. In anisotropic materials, the thermal conductivity typically varies with orientation; in this case $\mathrm{k}$ is represented by a second-order tensor. In non-uniform materials, $\mathrm{K}$ varies with spatial location. For many simple applications, Fourier's law is used in its one-dimensional form. In the x-direction,

$q_{x}=-k \frac{d T}{d x}$

\subsection{Integral form}

By integrating the differential form over the material's total surface $S$, we arrive at the integral form of Fourier's law:

$\frac{\partial Q}{\partial t}=-k \oint_{S} \nabla T \cdot d A$

Where (including the SI units):

$\frac{\partial Q}{\partial t} \quad$ Is the amount of heat transferred per unit time (in W), $\mathrm{dA}$ is an oriented surface area element (in $\mathrm{m}^{2}$ )

The above differential equation, when integrated for a homogeneous material of 1-D geometry between two endpoints at constant temperature, gives the heat flow rate as:

$\frac{\partial Q}{\partial t}=-k A \frac{\Delta T}{\Delta x}$

Where, $\mathrm{A}$ is the cross-sectional surface area, $\Delta T$ Is the temperature difference, $\Delta x$ Is the distance.

\subsection{Thermal Conductivity}

Thermal conductivity is the intrinsic property of a material which relates its ability to conduct heat. Heat transfer by conduction involves transfer of energy within a material without any motion of the maternal as a whole. Conduction takes place when a temperature gradient exists in a solid (or stationary fluid) medium. Conductive heat flow occurs in the direction of decreasing temperature because higher temperature equates to higher molecular energy or more molecular movement. Energy is transferred from the more energetic to the less energetic molecular when neighboring molecular collides.

Therefore, thermal conductivity is defined as the quantity of heat transmitted through a unit thickness in a direction normal to a surface of unit area due to a unit temperature gradient.

The rate of loss of heat energy from one end plate $=\frac{d E}{d t}$

And since $E=m c$

Where $\mathrm{E}=$ heat energy, $\mathrm{m}=$ mass of disc and $\mathrm{c}=$ specific heat capacity.

Then $\frac{d E}{d t}=m c\left(\frac{d \theta}{d t}\right)$

$\frac{d E}{d t}$ Is the rate of loss of heat from the end plate. Hence, knowing $\frac{d E}{d t}$, a value for $\frac{d E}{d t}$ can be found.

The value for the thermal conductivity $\mathrm{K}$ of the samples can now be calculated from

$\frac{d E}{d t}=\frac{K A\left(\theta_{2}-\theta_{1}\right)}{x}$

Where $\theta_{1}$ and $\theta_{2}$ are the readings recorded from the thermometers, $\mathrm{A}$ is the surface area of the disc $\left(\pi \mathrm{r}^{2} \mathrm{x}\right), \mathrm{x}=$ thickness of the sample, $r=$ radius of the disc

The factors affecting thermal conductivity are: The density of material, moisture of material and ambient temperature

\subsection{Working Principle of A Lee Disc}

This experiment method involves placing the wooden material between two specifically designed discs. After ensuring the temperature across the discs is constant, one of the discs should be heated to a certain temperature, after which the heating source should be removed. Heat will move from one disc to the other but must go through the material first, which will lead to further heat loss. By measuring the difference in temperature of the two discs, it is possible to determine the thermal conductivity of the material between the discs.

At the steady state rate of heat flowing into the system is equal to the rate of heat flowing out of a system.

\section{MATERIALS}

For this study to be carried out effectively the ceiling samples (Plaster of Paris (POP), Polyvinyl chloride (PVC), Asbestos and Aesthetic timber) were obtain from Jalingo market and were shaped into different thickness and diameter. The following materials were used in measuring the thermal conductivity of the ceiling sample.

a. Three copper discs A, B and C with a hole drilled in them. 
b. Three thermometers $T_{A}, T_{B}$ and $T_{C}$ which are to be inserted in the holes.

c. The roofing ceiling sample prepared in the form of disc having the same diameter as the copper disc.

d. A heat disc (heating element).

e. A wooden frame for clamping the disc together.

f. A voltmeter, an ammeter, a rheostat, a plug key and a 6 volt battery.

g. A stop watch.

h. Groundnut oil.

\subsection{Theory}

In this work $\theta_{\mathrm{A}}, \theta_{\mathrm{B}}$ and $\theta_{\mathrm{C}}$ represent the temperatures in excess of room temperature of discs $\mathrm{A}, \mathrm{B}$ and $\mathrm{C}$ respectively. When steady state has been reached, let $\frac{d e}{d t}$ represent the rate of emission of heat from the exposed surfaces measured in $\mathrm{Jm}^{-}$ ${ }^{1} \mathrm{~S}^{-1}$ per ${ }^{0} \mathrm{C}$ excess temperatures. If it is assumed that the temperature of the specimen $\mathrm{S}$ is the mean of the temperatures of $\mathrm{A}$ and $\mathrm{B}$, the total heat emitted per second is given, by

$\frac{Q}{t}=\frac{d e}{d t} a_{A} \theta_{A}+\frac{d e}{d t} a_{S}\left(\frac{\theta_{A}+\theta_{B}}{2}\right) \frac{d e}{d t} a_{B} \theta_{B}+\frac{d e}{d t} a_{C} \theta_{C}$

Where $a_{A}, a_{B}, a_{C}$ and $a_{S}$ are the exposed surface areas of A, B, $\mathrm{C}$ and $\mathrm{S}$ respectively. Now the heat emitted per second is all supplied by the heating element. This is given by

$\frac{Q}{t}=\mathrm{IV}\left(\mathrm{JS}^{-1}\right)$

Where $\mathrm{I}$ is the current measured in amperes end $\mathrm{V}$ is the potential drop in volts across the heating element.

Equations (2.4) and (2.5) are equal. Hence,

$I V=\frac{d e}{d t} a_{A} \theta_{A}+\frac{d e}{d t} a_{S}\left(\frac{\theta_{A}+\theta_{B}}{2}\right) \frac{d e}{d t} a_{B} \theta_{B}+\frac{d e}{d t} a_{C} \theta_{C} \ldots \ldots$

Hence

$\frac{d e}{d t}=$

$\frac{I V,}{a_{A} \theta_{A}+a_{S}\left(\frac{\theta_{A}+\theta_{B}}{2}\right) a_{B} \theta_{B}+a_{C} \theta_{C}}$

The heat conducted through S per second is given by

$q=k A \frac{\theta_{B}-\theta_{A}}{d}$

Where $\mathrm{A}$ is the cross sectional area of $\mathrm{S}, \mathrm{d}$ and $\mathrm{K}$ are the thickness and thermal conductivity of $\mathrm{S}$ respectively.

Now all the heat entering $\mathrm{S}$ from $\mathrm{B}$ does not pass into A since some of it is emitted from the curved surface of $\mathrm{S}$. the heat flowing through $\mathrm{S}$ is therefore taken as the mean of the heat entering $\mathrm{S}$ from $\mathrm{B}$ and that leaving $\mathrm{S}$ for $\mathrm{A}$. The heat entering $\mathrm{s}$ from $\mathrm{B}$ is that which is emitted by $\mathrm{S}$ and $\mathrm{A}$ together. It is given by

$\frac{d e_{A S}}{d t}=\frac{d e}{d t} a_{A} \theta_{A}+\frac{d e}{d t} a_{S}\left(\frac{\theta_{A}+\theta_{B}}{2}\right)$

The heat leaving $\mathrm{S}$ for $\mathrm{A}$ is that which is emitted by $\mathrm{A}$ alone. It is given by $e a_{A} \theta_{A}$. The mean of these is $\frac{1}{2}\left[e a_{A} \theta_{A}+e a_{S}\left(\frac{\theta_{A}+\theta_{B}}{2}\right)\right]=e a_{A} \theta_{A}+\frac{1}{4} e a_{S}\left(\theta_{A}+\theta_{B}\right) .$.

At steady state, (3.2) and (3.3) are equal, hence

$k A \frac{\theta_{A}+\theta_{B}}{d}=\frac{d e}{d t} a_{A} \theta_{A}+\frac{1}{4} \frac{d e}{d t} a_{S}\left(\theta_{A}+\theta_{B}\right)$

Therefore $k=\frac{d e}{a\left(\theta_{A}+\theta_{B}\right)} \frac{d e}{d t} a_{A} \theta_{A}+\frac{1}{4} \frac{d e}{d t} a_{S}\left(\theta_{A}+\theta_{B}\right) \ldots \ldots$

\subsection{Experimental Setup}

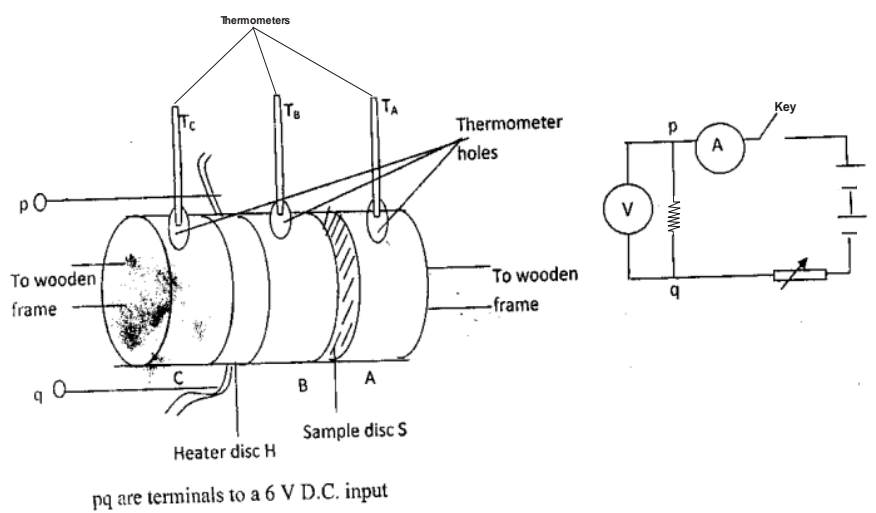

\subsection{Methodology}

Various roofing ceiling sample (Plaster of Paris, Polyvinyl chloride (PVC), Asbestos, aesthetic timber) the thermal conductivity to be determined the copper disc the roofing ceiling sample and heating element were placed together in the following order Disc A, sample S, Disc B, heating element and the Disc $\mathrm{C}$ with assurance that the holes in the discs were directed upwards. The thermometers $\mathrm{T}_{\mathrm{A}}$ and $\mathrm{T}_{\mathrm{B}}$ were inserted into the metal discs A and B place on either side of the sample Disc $\mathrm{S}$ and the space around the thermometer bulbs filled with oil to maximize thermal contact.

The heater disc was connected to a low voltage power supply and a steady state was reached where the temperature lie $90^{\circ}$. This is the temperature at which heat loss through sample to Disc B is equal to the heat gained by the sample from Disc A. the temperature reading and were recorded and the rate of heat loss from the Disc A was found which was achieved by removing Disc B, C and S and heating the Disc A directly to about $10^{\circ} \mathrm{C}$ above the steady state temperature earlier recorded.The heater Disc was removed and samples were placed, the cur at intervals of one minute was measured. The above procedure was repeated for each ceiling sample. The diameter for Disc B was determined using Venier caliper, the thicknesses of the samples were also determined using micrometer screw gauge and the beam balance was used to measure the mass of the Disc B. A cooling curve was plotted for each sample and the slope was also determined, then the thermal conductivity $(\mathrm{K})$ of each sample was determine using

$\frac{d e}{d t}=k A \frac{\theta_{B}-\theta_{A}}{d}$

Where $\mathrm{K}$ is the thermal conductivity to be determined 
A is the cross-sectional area of the ceiling samples and is given as

$A=\frac{\pi D^{2}}{4}$

$\frac{d e}{d t}$ Is the rate of heat loss and $\left(\theta_{B}-\theta_{A}\right)$ is the temperature difference.

\section{RESULTS AND DISCUSSION.}

\subsection{Data and calculation}

Table 4.1 is the materials specification of the selected roof ceiling material show the thickness cross sectional area diameter, and radios of the selected samples.

Table 4.1 specification of the parameters of the ceiling material samples

\begin{tabular}{|c|c|c|c|c|}
\hline Spacemen & Thickness(m) & $\begin{array}{c}\text { Cross } \\
\text { sectional } \\
\left(\mathrm{m}^{2}\right) \text { area }\end{array}$ & Diameter(cm) & Mass $(\mathrm{g})$ \\
\hline $\begin{array}{c}\text { Aesthetics } \\
\text { timber }\end{array}$ & $7.47 \times 10^{-3}$ & $1.32 \times 10^{-3}$ & 4.2 & $7.49 \times 10^{-3}$ \\
\hline POP & $7.47 \times 10^{-3}$ & $1.32 \times 10^{-3}$ & 4.2 & $11.58 \times 10^{-3}$ \\
\hline PVC & $7.47 \times 10^{-3}$ & $1.32 \times 10^{-3}$ & 4.2 & $9.64 \times 10^{-3}$ \\
\hline
\end{tabular}

\section{Calculation for Aesthetic Timber}

Emissivity (e)

$\mathrm{e}=\frac{I V}{a_{A} \theta_{A}+a_{S} \frac{\left(\theta_{A}+\theta_{B}\right)}{2} a_{B} \theta_{B}+a_{c} \theta_{C}}$

Parameters I = 0.5amp, V= 10vol, $a_{A}, a_{B}, a_{C} a_{S}=$ exposed surface areas of $\mathrm{A}, \mathrm{B}, \mathrm{C}$ and $\mathrm{S}$ respectively

$a_{A}=1.56 \times 10^{-3} \mathrm{~m}^{3}$ (for brass disc as calculated earlier), $\theta_{A}$ $=48.0^{\circ} \mathrm{C}, a_{S}=2 \pi r x=9.62 \times 10^{-4} \mathrm{~m}^{2} \quad$ (same size and thickness as timberwood)

$\left(\frac{\theta_{A}+\theta_{B}}{2}\right)=\left(\frac{48.0+84}{2}\right)=66.0^{\circ} \mathrm{C}$

$a_{A}=$ same with $a_{B}$ (brass disc same size ) $=1.56 \times 10^{-3} \mathrm{~m}^{3}$, $\theta_{B}=84 .{ }^{\circ} \mathrm{C}, a_{A}=1.56 \times 10^{-3} \mathrm{~m}^{3}$

$\mathrm{e}=\frac{I V}{a_{A} \theta_{A}+\mathrm{as}\left(\frac{\theta_{A}+\theta_{B}}{2}\right)+\theta_{B} a_{B}+a_{C} \theta_{C}}$

$\mathrm{e}$ $10 \times 0.5$

$\left(1.56 \times 10^{-3} \times 48\right)+\left(9.62 \times 10^{-4} \times 66\right)+\left(1.56 \times 10^{-3} \times 84\right)+\left(1.56 \times 10^{-3} \times 83\right)$

$\mathrm{e}=\frac{5.0}{0.07488+0.063492+0.13104+0.12948}=\frac{5.0}{0.398892}=12.53$

$\mathrm{e}=12.53 \mathrm{~W} / \mathrm{km}^{2} \mathrm{~s}$

Determine of $\mathrm{K}$ Arithmetically

$\mathrm{K}=\frac{x \times e}{A\left(\theta_{B}-\theta_{A}\right)} \times a_{A} \theta_{A}+\frac{1}{4} a_{s}\left(\theta_{A}+\theta_{B}\right)$

$\mathrm{e}=12.53 \mathrm{w} / \mathrm{m}^{2} \mathrm{~s}$

$x=$ thickness of aesthetic timber $=7.47 \times 10^{-3} \mathrm{~m}$

$a_{A}=1.56 \times 10^{-3} \mathrm{~m}^{2}$
$\theta_{A}=48.0^{0} \mathrm{C}$

$a_{s}=9.62 \times 10^{-4} \mathrm{~m}^{2}$

$\left(\theta_{A}+\theta_{B}\right)=(48+84)=132^{0} \mathrm{c}$

$\mathrm{A}=$ cross section area of $\operatorname{disc}=\pi r^{2}=1.32 \times 10^{-3} \mathrm{~m}^{2}$

$\left(\theta_{A}-\theta_{B}\right)=(84-48)=36.0^{\circ} \mathrm{C}$

$\mathrm{K}=\frac{7.47 \times 10^{-3} \times 12.53}{\left(1.32 \times 10^{-3} \times 36\right)} \times 1.56 \times \quad 10^{-3} \times 48 \quad+\frac{1}{4}[9.62 \times$ $10-4 \times(132)$

$\mathrm{K}=1.969678 \times 1.56 \times 10^{-3} \times 48$

$\mathrm{K}=0.1474894+0.031746=0.179 \mathrm{w} / \mathrm{mk}$

Density $(\rho)=$ mass/ volume

Mass of aesthetic timber $=7.49 \times 10^{-3} \mathrm{~kg}$

Volume $=\frac{4}{3} \pi r^{3}=3.609 \times 10^{-5} M^{3}$

$\rho=7.49 \times 10^{-3} / 3.609 \times 10^{-5}$

$\rho=207.54 \mathrm{~kg} / \mathrm{m}^{3}$

Thermal resistivity $\rho=\frac{1}{K}$

$\rho=\frac{1}{0.0179}=55.865$

$(\rho)=55.805 W^{-1} / \mathrm{mK}$

Table 4.2 The rate of cooling of sample A (Aesthetic Timber)

\begin{tabular}{|c|c|c|c|c|c|}
\hline $\begin{array}{c}\text { Time } \\
(\mathrm{t}) \text { min }\end{array}$ & $\begin{array}{c}\text { Temp } \\
(\mathrm{T})^{\mathrm{C}} \mathrm{C}\end{array}$ & $\begin{array}{c}\text { Time } \\
(\mathrm{t}) \mathrm{min}\end{array}$ & $\begin{array}{c}\text { Temp }(\mathrm{T}) \\
{ }^{\mathrm{C}} \mathrm{C}\end{array}$ & $\begin{array}{c}\text { Time }(\mathrm{t}) \\
\text { min }\end{array}$ & $\begin{array}{c}\text { Temp }(\mathrm{T}) \\
{ }^{\mathrm{C}} \mathrm{C}\end{array}$ \\
\hline 1 & 57.0 & 27 & 43.0 & 62 & 35.3 \\
\hline 2 & 56.0 & 28 & 42.2 & 63 & 35.2 \\
\hline 3 & 55.0 & 29 & 42.0 & 64 & 35.1 \\
\hline 4 & 54.8 & 30 & 41.7 & 65 & 35.0 \\
\hline 5 & 53.8 & 31 & 41.5 & 66 & 35.0 \\
\hline 6 & 53.0 & 32 & 40.9 & 67 & 34.9 \\
\hline 7 & 52.8 & 33 & 40.8 & 68 & 34.8 \\
\hline 8 & 52.0 & 34 & 40.3 & 69 & 34.8 \\
\hline 9 & 51.0 & 35 & 40.0 & 70 & 34.8 \\
\hline 10 & 50.5 & 36 & 39.8 & 71 & 34.5 \\
\hline 11 & 49.8 & 37 & 39.2 & 72 & 34.3 \\
\hline 12 & 49.5 & 38 & 39.0 & 73 & 34.2 \\
\hline 13 & 49.0 & 39 & 38.8 & 74 & 34.2 \\
\hline 14 & 48.2 & 40 & 38.2 & 75 & 34.2 \\
\hline 15 & 47.9 & 41 & 38.0 & 76 & 34.0 \\
\hline 16 & 47.2 & 42 & 38.0 & 77 & 34.0 \\
\hline 17 & 47.0 & 43 & 38.0 & 62 & 35.3 \\
\hline 18 & 46.2 & 44 & 37.9 & 63 & 35.2 \\
\hline 19 & 46.0 & 45 & 37.8 & 64 & 35.1 \\
\hline
\end{tabular}




\begin{tabular}{|l|l|l|l|l|l|}
\hline 20 & 45.5 & 46 & 37.8 & 65 & 35.0 \\
\hline 21 & 45.1 & 47 & 37.8 & 66 & 35.0 \\
\hline 22 & 44.8 & 48 & 37.7 & 67 & 34.9 \\
\hline 23 & 44.2 & 49 & 37.2 & 68 & 34.8 \\
\hline 24 & 44.0 & 50 & 37.0 & 69 & 34.8 \\
\hline 25 & 43.8 & 51 & 36.9 & 70 & 34.8 \\
\hline 26 & 43.2 & 52 & 36.8 & 71 & 34.5 \\
\hline
\end{tabular}

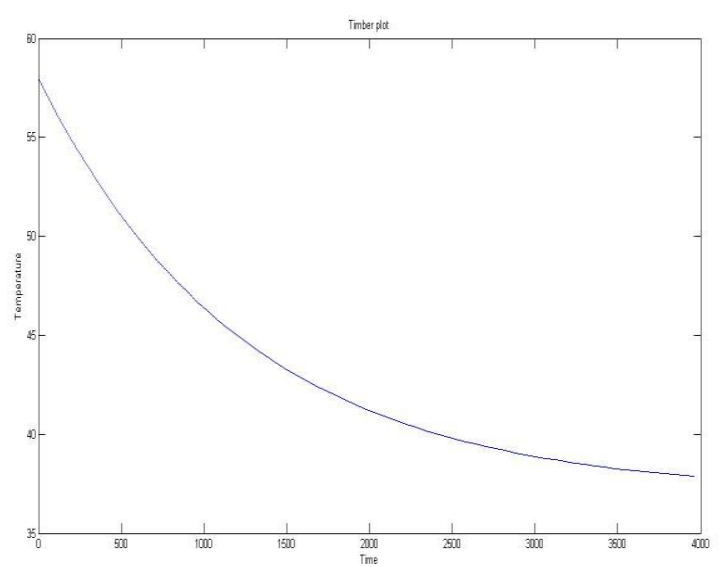

Fig 4.1 Temperature vs. Time for Aesthetic Timber

Determination of thermal conductivity (K) from the cooling curve i.e. using the value of $\frac{\Delta T}{\Delta t}$ (slope) of the curve.

From equation 1.6, $K=\frac{M_{c} \frac{\Delta T}{\Delta t} x}{A\left(\theta_{B}-\theta_{A}\right)}$,

Where $M_{C}=146 \times 10^{-3} \mathrm{~kg}, \frac{\Delta T}{\Delta t}($ Slope $)=6.58 \times 10^{-4}{ }^{\circ} \mathrm{C} / \mathrm{s}$

$A=1.32 \times 10^{-3} \mathrm{~m}^{2}, x=12.14 \times 10^{-3} \mathrm{~m} \quad \theta_{B}-\theta_{A}=$ $36^{\circ} \mathrm{C} \quad k=0.000245 \mathrm{~W} / \mathrm{mk}$

Resistivity $(\rho)=\frac{1}{K}=\frac{1}{0.000245}=4000 \mathrm{~W}^{-1} / \mathrm{mk}$

Calculation for Plaster of Paris (Pop)

Emissivity (e)

$$
\begin{aligned}
& \mathrm{e}=\frac{I V}{a_{A} \theta_{A}+a_{S}\left(\frac{\theta_{A+\theta_{B}}}{2}\right)+\mathrm{aв}_{\text {в }}+\mathrm{ac} \theta \mathrm{c}} \\
& a_{A}=2 \pi \mathrm{r} x=1.56 \times 10^{-3} \mathrm{~m}^{2} \quad \text { same as others } \\
& \theta_{A}=54^{\circ} \mathrm{C} \\
& a_{S}=2 \pi r=9.62 \times 10^{-4} \mathrm{~m}^{2} \text { same thickness } \\
& \left(\frac{\theta_{A}+\theta_{B}}{2}\right)=\left(\frac{54+70}{2}\right)=62^{\circ} \mathrm{C} \\
& a_{S}=\mathrm{same}=1.56 \times 10^{-3} \mathrm{~m}^{2} \\
& \theta_{B}=70^{0} \mathrm{C} \\
& a_{C}=1.56 \times 10^{-3} \mathrm{~m}^{2} \\
& \theta_{C}=70^{\circ} \mathrm{C}
\end{aligned}
$$

e $\frac{10 \times 0.5}{\left(1.56 \times 10^{-3} \times 54\right)+\left(9.62 \times 10^{-4} \times 62\right)+\left(1.50 \times 10^{-3} \times 70\right)+\left(1.50 \times 10^{-3} \times 70\right)}$ $\mathrm{e}=\frac{5}{(0.08424)+0.0059044+0.1092+0.1092}$

re $=13.80 \mathrm{~W} / \mathrm{m}^{2} s$

Thermal conductivity by calculation

$\mathrm{K}=\frac{x e \times \mathrm{a}_{\mathrm{A}} \theta_{\mathrm{A}}+\frac{1}{4} \mathrm{a} s\left(\theta_{\mathrm{A}}+\theta_{\mathrm{B}}\right)}{A\left(\theta_{\mathrm{B}}-\theta_{\mathrm{A}}\right)}$

Parameter $x=7.47 \times 10^{-3}$, e $=13.80 \mathrm{w} / \mathrm{m}^{2} s, a_{A}=$ $1.56 \times 10^{-3} \mathrm{~m}^{2}, \theta_{A}=54^{\Phi}, a_{S}=9.62 \times 10^{-4} \mathrm{~m}^{2}, \theta_{A}+$

\begin{tabular}{|c|c|c|c|}
\hline Time (t) min & Temp $(\mathrm{T})^{9} \mathrm{C}$ & Time(t) min & Temp $(\mathrm{T})^{\mathrm{s}} \mathrm{C}$ \\
\hline 1 & 61.0 & 26 & 47.0 \\
\hline 2 & 59.0 & 27 & 46.5 \\
\hline 3 & 59.0 & 28 & 46.5 \\
\hline 4 & 58.0 & 29 & 46.0 \\
\hline 5 & 57.0 & 30 & 46.0 \\
\hline 6 & 56.0 & 31 & 45.5 \\
\hline 7 & 56.0 & 32 & 45.5 \\
\hline 8 & 55.5 & 33 & 45.0 \\
\hline 9 & 55.0 & 35 & 45.0 \\
\hline 10 & 54.0 & 36 & 44.5 \\
\hline 11 & 53.5 & 37 & 44.5 \\
\hline 12 & 53.0 & 38 & 44.0 \\
\hline 13 & 52.5 & & \\
\hline 14 & 52.0 & & \\
\hline 15 & 51.0 & & \\
\hline 16 & 51.0 & & \\
\hline 17 & 50.5 & & \\
\hline 18 & 50.0 & & \\
\hline 19 & 49.0 & & \\
\hline 20 & 48.0 & & \\
\hline 21 & 48.0 & & \\
\hline 22 & 48.0 & & \\
\hline
\end{tabular}
$\theta_{B}=54+70=124^{\circ} \mathrm{c}, \mathrm{A}=\pi r^{2}=1.32 \times 10^{-3} \mathrm{~m}^{2}, \theta_{B}$ $-\theta_{A}=70-54=16^{\circ} \mathrm{c}$

$\mathrm{K}=0.44 \mathrm{~W} / \mathrm{mK}$

Thermal resistivity

$\rho=\frac{1}{K}=\frac{1}{o .44}=2.2678 \mathrm{~W}^{-1} \mathrm{mK}$

Density for pop

$\rho=\frac{\text { mass }}{\text { volume }}=\frac{11.58 \times 10^{-3}}{3.609 \times 10^{-3}}, \rho=320.86 \mathrm{~kg} / \mathrm{m}^{3}$

Table 4.3: The rate of cooling of sample B (POP) 


\begin{tabular}{|l|l|l|l|}
\hline 23 & 48.0 & & \\
\hline 24 & 47.0 & & \\
\hline 25 & 47.5 & & \\
\hline
\end{tabular}

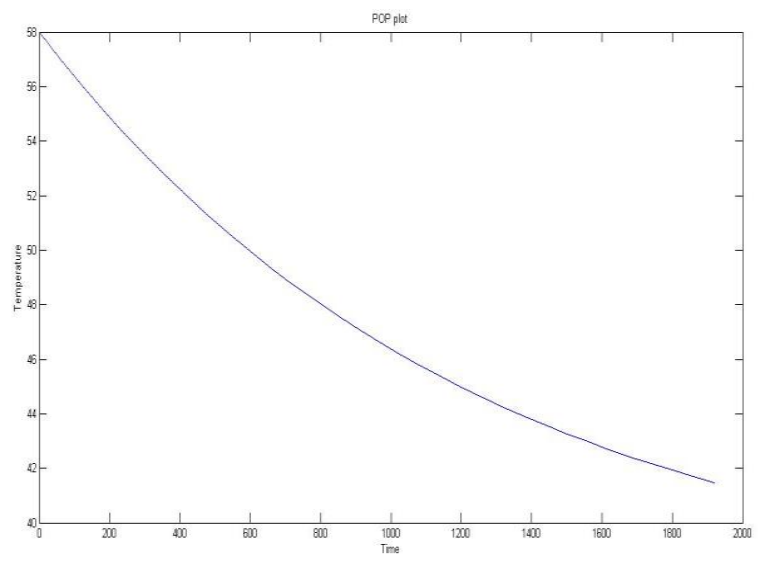

Temperature vs. Time for Plaster of Paris (POP)

Determination of thermal conductivity $(\mathrm{K})$ from the cooling curve i.e. using the value of $\frac{\Delta T}{\Delta t}$ (slope) of the curve.

From equation $1.6 \quad K=\frac{M_{C} \frac{\Delta T}{\Delta t} x}{A\left(\theta_{B}-\theta_{A}\right)} \quad$,Where $\quad M_{C}=$ $146 \times 10^{-3} \mathrm{~kg}, \frac{\Delta T}{\Delta t}$ (Slope) $=9.65 \times 10^{-4 \circ} \mathrm{C} / \mathrm{s}$

$A=1.32 \times 10^{-3} \mathrm{~m}^{2}, x=12.14 X 10^{-3} \mathrm{~m}, \theta_{B}-\theta_{A}=16^{\circ} \mathrm{C}$

$k=0.00080985 \mathrm{~W} / \mathrm{mk}$

Resistivity $(\rho)=\frac{1}{K}=\frac{1}{0.00080985}=1234.79 \mathrm{~W}^{-1} / \mathrm{mk}$

Calculation for Polyvinylchloride (Pvc)

Voltage $=\quad 10$

Diameter $\quad=\quad 4.2 \mathrm{~cm}$

Thickness $\quad=\quad 7.47 \times 10^{-3} \mathrm{~m}^{2}$

$a_{A}=1.56 \times 10^{-3} \mathrm{~m}^{2}$

$a_{S} \quad=\quad 9.62 \times 10^{-4} \mathrm{~m}^{2}$

$a_{B}=1.56 \times 10^{-3} \mathrm{~m}^{2}$

$a_{C}=1.56 \times 10^{-2} \mathrm{~m}^{2}$

$\theta_{A}=40^{\circ} \mathrm{c}$

$\theta_{B}=52^{\circ} \mathrm{c}$

$\theta_{C}=55^{0} \mathrm{c}$

Current $=0.5$ Ampere

Emissivity (e)

$\mathrm{e}=\frac{I V}{\partial_{A} \phi_{B}+a s\left(\frac{\phi_{A}+\phi_{B}}{2}\right)+\phi_{B \partial_{B}}+\emptyset_{C \partial_{C}}}$ e

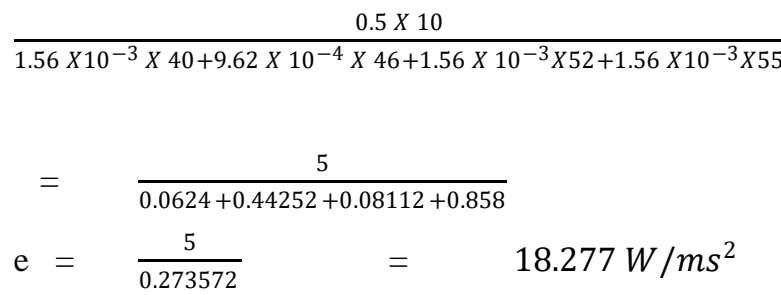

Thermal conductivity.( K)

$k=\frac{x X e}{A\left(\theta_{B}-\theta_{A}\right)} X \partial_{A} \theta_{A}+\frac{1}{4} \partial_{S}\left(\theta_{B}+\theta_{A}\right)$

$k=$

$\frac{7.47 \times 10^{-3} \times 18.277}{1.32 \times 10^{-3}(12)} \times 1.56 \times 10^{-3} \times 40+\frac{1}{4} 9.62 \times 10^{-4} \times 92$ $k=\frac{0.1365}{0.01584} \times 0.0624+0.022126$

$k=8.617 X 0.0624+0.022126=0.5377+0.0221$

$$
k=0.5598
$$

$$
k=0.56 \mathrm{~W} / \mathrm{mk}
$$

Resistivity $(\rho)$

$\rho=\frac{1}{k}=\frac{1}{0.5598}=1.79 \mathrm{~W}^{-1} / \mathrm{mk}$

Density $\delta=\frac{\text { Mass }}{\text { Volume }}$

Where mass of $\mathrm{PVC}=9.64 \times 10^{-3} \mathrm{~kg}$

Volume $=\frac{4}{3} \pi r^{3}=3.609 \times 10^{-5} \mathrm{~m}^{3}$ $\frac{9.64 \times 10^{-3}}{3.609 \times 10^{-5}}=267.11 \mathrm{~kg} / \mathrm{m}^{3}$

Table 4.4: The rate of cooling of sample C (PVC)

\begin{tabular}{|c|c|c|c|}
\hline Temp $\left({ }^{\circ} \mathrm{C}\right)$ & Time $(\mathrm{t}) \mathrm{min}$ & Temp $\left({ }^{\circ} \mathrm{C}\right)$ & Time $(\mathrm{t}) \mathrm{min}$ \\
\hline 58.0 & 0 & 42.0 & 19 \\
\hline 57.0 & 1 & 41.5 & 20 \\
\hline 56.0 & 2 & 41.5 & 21 \\
\hline 55.0 & 3 & 41.0 & 22 \\
\hline 54.0 & 4 & 40.5 & 23 \\
\hline 53.0 & 5 & 40.0 & 24 \\
\hline 52.0 & 6 & 39.0 & 25 \\
\hline 50.5 & 7 & 39.0 & 26 \\
\hline 49.5 & 8 & 38.0 & 27 \\
\hline 49.0 & 9 & 37.5 & 28 \\
\hline 48.0 & 10 & 37.0 & 29 \\
\hline 47.0 & 11 & 37.0 & 30 \\
\hline 46.0 & 12 & 37.0 & 31 \\
\hline 45.5 & 13 & 37.0 & 32 \\
\hline & & & \\
\hline
\end{tabular}




\begin{tabular}{|l|l|l|l|}
\hline 45.0 & 14 & 36.9 & 33 \\
\hline 44.5 & 15 & 36.0 & 34 \\
\hline 44.0 & 16 & 36.0 & 35 \\
\hline 43.0 & 17 & 35.0 & 36 \\
\hline 42.0 & 18 & 42.0 & 19 \\
\hline
\end{tabular}

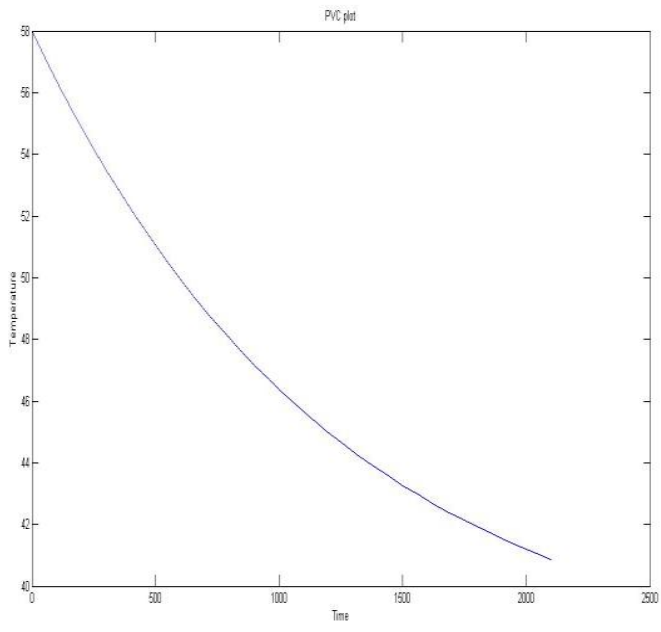

Fig. 4.3: Temperature vs. Time for Polyvinylchloride (PVC)

Determination of thermal conductivity $(\mathrm{K})$ from the cooling curve i.e. using the value of $\frac{\Delta T}{\Delta t}$ (slope) of the curve.

From equation $1.6 K=\frac{M_{c} \frac{\Delta T}{\Delta t} x}{A\left(\theta_{B}-\theta_{A}\right)}$

Where $M_{C}=146 \times 10^{-3} \mathrm{~kg}$

$\frac{\Delta T}{\Delta t}($ Slope $)=9.54 \times 10^{-3 \circ} \mathrm{C} / \mathrm{s}$

$A=1.32 \times 10^{-3} \mathrm{~m}^{2}$

$x=12.14 X 10^{-3} \mathrm{~m}$

$\theta_{B}-\theta_{A}=12^{\circ} \mathrm{C}$

$k=\frac{146 \times 10^{-3} \times 9.54 \times 10^{-3} \times 12.14 \times 10^{-3}}{1.32 \times 10^{-3}(12)}=\frac{1.6909 \times 10^{-5}}{0.01584}=$

$0.0010675 \mathrm{watt} / \mathrm{m} k$ Resistivity $(\rho)=\quad \frac{1}{K}=\frac{1}{0.0010675}=$ $936.77 W^{-1} / m k$

Table 4.5 Calculated thermal properties of the selected ceiling materials

\begin{tabular}{|c|c|c|c|c|}
\hline Specimens & $\begin{array}{c}\text { Thermal } \\
\text { conductivity } \\
(\mathrm{W} / \mathrm{mk})\end{array}$ & $\begin{array}{c}\text { Thermal } \\
\text { resistivity } \\
(\mathrm{mK} / \mathrm{W})\end{array}$ & $\begin{array}{c}\text { Density } \\
\left(\mathrm{Kg} / \mathrm{m}^{3}\right)\end{array}$ & Emissivity(W/m $\left.{ }^{2} \mathrm{~s}\right)$ \\
\hline POP & $\begin{array}{c}8.0985 \mathrm{X} \\
10^{-4}\end{array}$ & 1234.79 & 320.86 & 13.80 \\
\hline PVC & $\begin{array}{c}1.0675 \times 10^{-} \\
3\end{array}$ & 936.77 & 267.11 & 18.277 \\
\hline $\begin{array}{c}\text { AESTHETIC } \\
\text { TIMBER } \\
\text { WOOD }\end{array}$ & $2.45 \times 10^{-4}$ & 4000 & 207.54 & 12.53 \\
\hline
\end{tabular}

\subsection{Discussion of Result}

Table 4.1 is the material specification of the selected material showing the thickness, cross sectional area radius and diameter of the selected samples.

Table 4.2, 4.3 and 4.4 and fig. 4.1, 4.2 and 4.3, shows the cooling rate of the selected material. The result shows that Aesthetic timber wood Exhibits the best cooling rate followed by Plaster of Paris (POP) then Polyvinyl chloride (PVC) The cooling curve of the three sampled material taken at every one minutes shows that all the material have a similar cooling pattern.

Table 4.5 Present the calculated thermal properties such as thermal conductivity, thermal resistivity etc. for the three selected materials. The result shows that all the materials are good insulating materials since their thermal conductivity fall within the conductivities of construction and heat. Insulating materials given by (Mahhrery 1982) as $0.023-29 \mathrm{Wm}^{-1} \mathrm{k}^{-1}$.

Plaster of Paris (POP) has a thermal conductivity of $8.0985 \times 10^{-4}$ watt $/ \mathrm{mK}$ resistivity of $1234.79 \mathrm{mk} / \mathrm{watt}$ Emissivity of $13.80 \mathrm{watt} / \mathrm{m}^{2} \mathrm{x}$ and Density of $320.86 \mathrm{k} / \mathrm{m}^{3}$ Aesthetic timber wood has a thermal conductivity of $0.00025 \mathrm{watt} / \mathrm{mK}$ Thermal resistivity of $4000 \mathrm{mk} / \mathrm{watt}$ emissivity of $12.53 \mathrm{watt} / \mathrm{m}^{2} \mathrm{x}$ And Density of $207.54 \mathrm{~kg} / \mathrm{m}^{3}$ Polyvinyl chloride (PVC) has the thermal conductivity of $1.0675 \times 10^{-3}$ watt $/ \mathrm{mK}$ Thermal resistivity of $936.77 \mathrm{mk} / \mathrm{watt}$ emissivity of $18.277 \mathrm{watt} / \mathrm{m}^{2} \mathrm{x}$ And Density of $267.11 \mathrm{k} / \mathrm{m}^{3}$ theoretically a substance with large thermal conductivity value is a good conductor of heat. One with a small thermal conductivity value is a poor heat conductor that is a good insulator. In other word a good insulation material will have a high resistivity value.

\section{CONCLUSION}

The result obtained in this study has shown that all the selected roof ceiling materials have low thermal conductivity and high thermal resistivity which show that they are good insulating material and can be used for roofing in the tropical regions. This study also provided useful information on the thermal conductivity to ascertain which of the roof ceiling materials under test has higher conductivity.

\subsection{Recommendation}

From the result in table 4.5 it is observed that among the material studied Aesthetic Timber wood provide the best thermal insulation since it has the lowest thermal conductivity (highest thermal resistivity) followed by POP the PVC from the result of this research, the best roof ceiling material to be used in tropical regions is aesthetic timber wood and POP. 


\section{REFERENCE}

[1] Ayugi, G. (2009). "Thermal properties of selected Materials for Thermal Insulation available in Uganda 'B.Sc. Thesis Dept. of Physics. MakerereUniversity.

[2] Etuk, S. E., Akpabio, L. E., \&.Akpabio, K. E.(2005) "Determination of the Thermal properties of CocosNucifera Trunk for Predicting Temperature variation with its Thickness," The Arabian Journal and Engineering, vol. 30, 1A,pp, 121-126.

[3] Folaranmi Joshua (2009). Effects of additives on the thermal conductivity of clay. Leornado journal of science ISSN 1583-0233 P 74-77

[4] Gesa, F. Newton, Atser A. Roy \&Aondoakaa, I. Solomon. (2014) "Investigation of the Thermal Insulation Properties of Selected Ceiling. Materials used in Makurdi Metropolis (Benue State, Nigeria)," American Journal of Engineering Research.Vol. 3, pp. 245-250

[5] Hailemariam .H and Wuttke F. (2019) Effects of the stress on the thermal conductivity of soils

[6] European conference on soil and geotechnical engineeringISBN 9789935-9436-1-3

[7] Lattimer, B. Y.\& J. Ouellette,(2006) "Properties of Composite Materials for thermal Analysis Involving Fires," Composites: Part A, Vol. 37, No. 7, 2006, pp. 1068-1081
[8] Michael, C. O., Evelyn, O., Ephraim, O. C., Chinedu, E. E. \&Arusuedfe, J. O. (2012). Comparison of the Thermal Properties of Asbestos and polyvinyl chloride (PVC) Ceiling Sheets. Materials Sciences and Vol. 3, pp. 240-244

[9] Michels.C.Lamberts,R.\&SGuths,(2008)“Theoretical/Experimental , Comparison of Heat Flux Reduction in Roofs Achieved through the Use of Reflective Thermal Insulators," Energy and Buildings, Vol. 40, No. 4, 2008, pp. 438- 444.

[10] Ombaka Ochieng (2016). Characterization and classification of clay minerals for potential applications in Rugi ward,Kenya. African journal of environmental science and technology

[11] Sam Sheard; (2012). Material handbook on thermal conductivity values. CRC Press. pp. 304

[12] Suman, B. M.\& R. K. Srivastava. (2009). Influence of Thermal Insulation on Conductive Heat Transfer through Roof Ceiling Construction.Journal of Scientific \& Industrial Research, Vol. 68, pp. 248-251.

[13] Sundbergay, Louis (1985). Determination of Thermal properties of Cocos Trunk Variation with its Thickness. Arabian Journal for Science and Engineering, Vol.30, N0.1A.

[14] Utas frank (2015). "Thermal Insulation Handbook", New York: Published by McGray-Hill Book Company. The Exact Analytical Conduction Toolbox contains a variety of transient

[15] expressions for heat conduction, along with algorithms and computer code for obtaining precise numerical values. 